\title{
Urban Thermal Risk
}

\section{Dimitra Founda}

check for updates

Citation: Founda, D. Urban Thermal Risk. Atmosphere 2021, 12, 466. https://doi.org/10.3390/atmos12040466

Received: 2 April 2021

Accepted: 6 April 2021

Published: 8 April 2021

Publisher's Note: MDPI stays neutral with regard to jurisdictional claims in published maps and institutional affiliations.

Copyright: (C) 2021 by the author. Licensee MDPI, Basel, Switzerland. This article is an open access article distributed under the terms and conditions of the Creative Commons Attribution (CC BY) license (https:/ / creativecommons.org/licenses/by/ $4.0 /)$.
Institute for Environmental Research and Sustainable Development, National Observatory of Athens, 11810 Athina, Greece; founda@noa.gr

Global warming is accelerating and according to the World Meteorological Organization (WMO), the decade from 2011 to 2020 was the warmest recorded decade ever. In a "warming planet", the changes in the mean temperature are accompanied by simultaneous increases in the intensity and frequency of climatic extremes, like exceptionally hot weather. Heat waves (HWs) in particular-broadly understood as prolonged periods of excess heat-rank among the most hazardous climatic extremes, with profound impacts on human health and natural systems. Apart from climatic factors, exposure and sensitivity (or vulnerability) of a population to thermal risk involves a variety of socioeconomic and demographic components, like urbanization levels, population ageing, economic status, adaptive capacity, and others. Today, urban areas are home for more than $55 \%$ of the global population, and this proportion is going to increase in the near future. Urban residents are more vulnerable to HWs due to the added effect of the Urban Heat Island (UHI), a phenomenon that makes cities hotter than the surrounding non-urban sites, but also the synergistic reactions between UHIs and HWs that exacerbate the strength of UHIs and increase heat stress. This Special Issue (SI) presents a number of innovative studies on the topic, focusing on urban areas. Long-term trends in HWs and heat stress metrics at cities of different climate and size, and simulations of the urban thermal environment using air temperature and/or other thermal (bioclimatic) indices, but also interactions between HWs and UHIs and social components affecting urban thermal risk, are addressed and highlighted in this SI.

In their study, Founda et al. [1] assessed exposure of the European population to extreme weather and thermal stress, by analysing historical climatic data spanning several decades at cities of different background climates, ranging from warm Mediterranean cities like Athens (Greece) to very cold cities of northern Europe like Helsinki or Oulu (Finland). The results demonstrated that hot extremes and "great discomfort" conditions based on bioclimatic indices have almost tripled during the last two or three decades, especially at southern cities, while northernmost cities have experienced an unprecedented increase in HWs during the last decade, when heat-related "discomfort" conditions have also become increasingly more frequent compared to the 1970s or 1980s, when such conditions were absent.

The papers by Katavoutas and Founda [2] and Rasilla et al. [3] focus on Mediterranean cities and study the characteristics and trends of HWs metrics over long periods, as well as the synergies between HWs and UHIs. The Mediterranean has been assigned as one of the most responsive to climate change areas in the world, with respect to the observed and projected thermal risk. Thermal comfort/discomfort conditions were assessed using both simple indicators, like the Heat Index (HI) or Humidex (HD), and advanced (or rational) thermal indicators, which are based on a human heat balance model, like the Universal Thermal Comfort Index (UTCI) and the Physiologically Equivalent Temperature (PET).

Rasilla et al. [3] analysed a centennial record of air temperature in Madrid and found a shift by $+1.5^{\circ} \mathrm{C}$ in the mean air temperature during the recent period 1980-2017 compared to the previous period 1948-1979, accompanied by a significant increase in the frequency and duration of HWs after the 1980s. The authors also studied UHI intensity using air 
temperature records at different urban and non-urban stations and land surface temperature (LST) images from MODIS products to assess the surface UHI (SUHI), and investigate the possible synergistic interactions between UHIs and HWs. Positive feedbacks between UHIs and HWs are reported in this study, with exacerbation of the nocturnal rather than daytime UHI intensity during HW episodes. In regards to the surface UHI, both diurnal and nocturnal SUHI were found to increase during HWs but without symmetrical magnitudes of increase, with the average value of the nocturnal SUHI reaching $2{ }^{\circ} \mathrm{C}$, being twice as high the diurnal one.

In their study, Katavoutas and Founda [2] introduce the Urban Heat Stress Intensity (UHSI) index-in-line with the well-known Urban Heat Island Intensity (UHII) indexusing bioclimatic instead of air temperature indices and assessing the difference of heat stress conditions between urban and non-urban sites during HW and non-HW periods. The analysis demonstrated a robust intensification of nighttime heat stress conditions in urban, compared to non-urban sites during severe heat waves, implying positive feedbacks between HWs and UHSI. Nevertheless, severe heat waves almost equalized heat stress conditions between urban and non-urban sites during midday. The results were very consistent between the two bioclimatic indicators used to assess heat stress in the study, namely the simple, well-known Humidex (HD) and the rational UTCI, taking into consideration the mechanisms of heat exchange and the thermo-physiological process on the human body.

Using a single-level Urban Canopy Model (UCM), combined with observations and Landsat satellite data, Chen et al. [4] simulated high-resolution spatial distribution of air temperature, humidity, heat index, and UHI intensity in a very effective way, in Suzhou City (China), suggesting the validity of the model to capture microclimate features within the urban environment, necessary for urban climate analysis and adaptation/mitigation studies. The spatial distribution pattern of urban heat islands was found to be highly consistent with urban land cover fraction, with the annual average UHI intensity ranging from 1.2 to $0.8^{\circ} \mathrm{C}$, depending on the density and ventilation of urban areas.

Despite any observed or simulated trends in indices related to thermal stress and the possible synergies between HWs and UHIs in urban environments, the health outcome of extreme temperatures is also subject to a number of additional, social factors, including population acclimatization, psychology, subjectivity to thermal comfort/stress, and behavioural practices. The paper by Elnabawi and Hamza [5] addresses some of these components. The study conducts a critical assessment of the outdoor thermal comfort studies from a behavioural point of view, paying particular attention to perceptions of outdoor thermal comfort and the use of outdoor space in the context of urban planning. The study discusses limitations, weaknesses, and gaps of the adopted methods in literature studies, while underlining the need for data that capture the subjective sensation of urban surroundings in order to reveal a wider perspective of the evaluation of outdoor thermal comfort. In this direction, the authors also propose a comprehensive framework for examining the behavioural aspect of outdoor thermal comfort, linking the microclimatic environment with subjective thermal assessment and social behavior.

In the context of a rapidly warming and urbanizing environment, I believe that this SI will be a useful contribution to the literature, and will inspire future work on the topic.

Funding: This research received no external funding.

Institutional Review Board Statement: Not applicable.

Informed Consent Statement: Not applicable.

Acknowledgments: The Editor would like to thank all authors for the high-quality contributions in this SI, and the reviewers for their time devoted to the evaluation and improvement of the manuscripts. Additionally, the Editor would like to thank the Editors and Technical Staff of the "Atmosphere" (MDPI) Journal, for their overall support and cooperation.

Conflicts of Interest: The authors declare no conflict of interest. 


\section{References}

1. Founda, D.; Pierros, F.; Katavoutas, G.; Keramitsoglou, I. Observed Trends in Thermal Stress at European Cities with Different Background Climates. Atmosphere 2019, 10, 436. [CrossRef]

2. Katavoutas, G.; Founda, D. Response of Urban Heat Stress to Heat Waves in Athens (1960-2017). Atmosphere 2019, 10, 483. [CrossRef]

3. Rasilla, D.; Allende, F.; Martilli, A.; Fernández, F. Heat Waves and Human Well-Being in Madrid (Spain). Atmosphere 2019, 10, 288. [CrossRef]

4. Chen, Y.; Zhang, N.; Zhu, Y. High-Resolution Simulations of the Urban Thermal Climate in Suzhou City, China. Atmosphere 2019, 10, 118. [CrossRef]

5. Elnabawi, M.H.; Hamza, N. Behavioural Perspectives of Outdoor Thermal Comfort in Urban Areas: A Critical Review. Atmosphere 2020, 11, 51. [CrossRef] 